\title{
Immunization to learned helplessness in appetitive noncontingent contexts
}

\author{
PILAR FERRÁNDIZ \\ Universidad Complutense, Madrid, Spain \\ and \\ ANTONIO PARDO \\ Universidad Autónoma, Madrid, Spain
}

\begin{abstract}
We examined immunization against learned helplessness in 36 dogs. The experiment consisted of five phases: (1) appetitive contingent training, (2) immunization training, (3) inescapable noise training, (4) recovery, and (5) an appetitive noncontingent test. There were six groups: (1) a group immunized by controllable and predictable noise, (2) a group immunized by controllable but unpredictable noise, (3) a group immunized by uncontrollable but predictable noise, (4) a group given uncontrollable and unpredictable noise during immunization training, (5) a group not submitted to any treatment during the immunization phase, followed by uncontrollable noise, and (6) a group not submitted to any treatment. The immunization effect was assessed by measuring the acquisition of an appetitive response when food was not contingent upon responding. Our results demonstrate that the immunization effect can be observed in a noncontingent appetitive context. The effects of escapable noises that ensure immunization against the motivational deficit and predictable noises that immunize against the associative deficit seem to be additive.
\end{abstract}

According to learned helplessness theory (Overmier \& Seligman, 1967; Seligman, 1972, 1975), subjects previously exposed to inescapable shocks are unable to learn escape responses when escape is possible. This interference effect may occur because a subject exposed to inescapable shock acquires the expectancy that its responses and shock termination are independent, which results in both a motivational deficit (initiation of voluntary responses decreases) and an associative deficit (the expectancy interferes with the learning of new responsereinforcer relationships). This effect has been widely demonstrated with different types of responses (Altenor, Kay, \& Richter, 1977), using different sorts of reinforcement (Seligman, 1975), independently of the subjects' characteristics (Ferrándiz, Olea, \& Pardo, 1985), and in different motivational contexts (Rosellini \& DeCola, 1981; Rosellini, DeCola, \& Shapiro, 1982).

But learned helplessness theory also suggests that it is possible to immunize a subject against the deficits produced by exposure to uncontrollable events (e.g., inescapable shock) if previous experiences with controllable events have led the subject to acquire the expectancy that its response and the consequences that follow are related. Seligman and Maier (1967) found that dogs trained to escape a series of shocks and then put through

Correspondence concerning this article should be addressed to either Pilar Ferrándiz, Departamento de Psicología (Procesos Básicos). Universidad Complutense, Campus de Somosaguas, 28023 Madrid. Spain, or Antonio Pardo, Departamento de Psicología Básica, Universidad Autónoma, Cantoblanco, 28049 Madrid, Spain. an inescapable shock treatment showed no deficit in their escape responding when they were once again permitted to escape shock. Notwithstanding several demonstrations of this immunization effect (Seligman \& Groves, 1970; Seligman, Rosellini, \& Kozak, 1975; Williams \& Maier, 1977), its generality is not certain (see Anisman, Irwin, Beauchamp, \& Zacharko, 1983).

Warren, Rosellini, Plonsky, and DeCola (1985, Experiments 1 and 2) found that when the test phase was carried out in an appetitive noncontingent context in which rats were permitted to perform a previously foodreinforced response under a scheme of random-time noncontingent reinforcement, immunization did not appear. To find out if such a failure to obtain immunization was due either to the fact that different motivational contexts had been used in the training (aversive) and the test (appetitive) phases, or to the utilization of a noncontingent test situation, Warren et al. carried out a third experiment, in which a contingent appetitive test was used and different motivational contexts in training and testing were maintained. They obtained the immunization effect in this paradigm. Aside from representing the first empirical demonstration of the possibility of obtaining immunization by using different motivational contexts for the training and test phases, these results, together with those in their Experiments 1 and 2, seem to show that immunization to helplessness cannot be obtained in situations in which the immunization effect is evaluated by means of an appetitive test in which the responses and reinforcements are independent of each other (i.e., by using a noncontingent appetitive test). 
Warren et al. (1985) questioned some of the theoretical viewpoints that could account for their results-for example, the role of the interaction between the organism's expectation about the existing relationship between its responses and the reinforcements received and the information supplied by the situation concerning such a relationship (Alloy \& Tabachnik, 1984). But we propose an alternative explanation that not only does not contradict learned helplessness theory, but, if proved, would strengthen one of its latest reformulations (Overmier, 1985).

Learned helplessness theory, as modified by Seligman, Maier, and Solomon (1971), attributes the motivational, associative, and emotional deficits experienced by an animal after it has been subjected to inescapable shocks to only one factor: the uncontrollable nature of the shocks employed (Maier \& Seligman, 1976). If this is so, it should be expected that after exposure to inescapable shock, the three aforementioned deficits should appear together. However, Jackson, Alexander, and Maier (1980), for example, discovered that an associative deficit could occur in the absence of a motivational deficit: the animals in that study proved incapable of learning new responses but still emitted voluntary responses.

An explanation of this phenomenon, which complements learned helplessness theory, suggests that the helplessness syndrome depends not on one causal factor (uncontrollability), but on two factors: uncontrollability and unpredictability. In fact, the shocks employed in experiments designed to induce helplessness are generally not only uncontrollable but are also unpredictable (Overmier, 1985; Overmier \& Wielkiewicz, 1983). Overmier suggested that the two factors are independent (cf. Dess, Linwick, Patterson, Overmier, \& Levine, 1983), the uncontrollable events being responsible for the motivational deficit and the unpredictable events being responsible for the associative deficit. The importance of predictability in this account is in accord with findings that animals prefer predictable shocks to unpredictable shocks (Abbott, 1985; Badia, Harsh, \& Abbott, 1979), and that the stress reaction to shocks is often attenuated when the shocks are predictable (Abbott, Schoen, \& Badia, 1984; Dess et al., 1983).

In accordance with this suggestion, experience with controllable but unpredictable events should affect only the shock uncontrollability component; complete immunization should be possible only by training subjects with controllable and predictable stimuli.

Here arises the problem that the present study was designed to solve. Immunization has been obtained in both aversive motivational contexts (Williams \& Maier, 1977) and appetitive contexts (Mullins \& Winefield, 1977) by using different types of escape responses in the training and test phases (Seligman et al., 1975), and by using different motivational contexts in the training and test phases (Warren et al., 1985). All of these effects occurred when reinforcement during testing was responsecontingent.
In noncontingent tests, the immunization effect has not been observed. However, in noncontingent tests, not only should inescapably shocked animals be more sensitive than nonshocked animals to the response-reinforcer independence (Rosellini, DeCola, Plonsky, Warren, \& Stilman, 1984), but immunized animals should behave like nonshocked animals. Thus, inescapably shocked animals should make fewer responses than nonshocked animals, whereas immunized animals should respond as frequently as nonshocked animals.

Therefore, in this work, we hypothesize that it is possible to immunize an organism against the deficits produced by exposure to inescapable aversive stimuli, even when performance is assessed in noncontingent appetitive contexts. But, for this purpose, controllable and predictable stimuli must be used in the training phase in order to ensure immunization against the motivational and associative deficits, respectively.

\section{METHOD}

\section{Subjects}

The subjects were 36 dogs with a mean age of 17.6 months, ranging from 9 to 24 months old. During the week prior to the experiment, the dogs were put through a food-deprivation program to reduce their weights to $95 \%$ of their normal weights.

\section{Apparatus}

Two LA 58010 programming units were used to present stimuli. A 120-dBA, 3800-Hz noise was the aversive stimulus. A feeding trough and two response levers were specially designed for this experiment. The operant conditioning unit was a Campden Model 105 with a Campden Model 565 chronometer. Four brick-panel isolation compartments were used, each measuring $1.90 \times 1.90 \times$ $1.60 \mathrm{~m}$ with a $10 \times 7.5 \mathrm{~cm}$ glass window through which the dogs could be observed. The first chamber was used in appetitivecontingent training and in the appetitive noncontingent test. The feeding trough was placed $30 \mathrm{~cm}$ above the floor, centered on one of the walls. A $5 \times 5 \mathrm{~cm}$ response lever was placed on the floor under the feeding trough $20 \mathrm{~cm}$ from the wall; when it was pressed, food was delivered to the trough. The operant conditioning unit was placed outside the compartment, in the next room. The second compartment was used during the immunization period. The noise stopped when an $11 \times 22 \mathrm{~cm}$ response lever, placed in the center of this compartment, was pressed. The noise source was placed in one of the walls, $150 \mathrm{~cm}$ above the floor. A 200 -W lightbulb was placed in the center of one of the walls. The bulb was used to signal the occurrence of the noise for some of the experimental groups. The third compartment was used during inescapable noise training; the lever in this compartment was identical to the one used in immunization training, but was disconnected, so the noise did not stop when the lever was pressed. The noise source was placed in the same place as in the second compartment. The fourth compartment was used for the recovery phase. In addition to the four cubicles, each dog had its usual home cage.

\section{Procedure}

The experiment consisted of five phases: (1) appetitive-contingent training, (2) immunization training, (3) inescapable noise training, (4) recovery, and (5) an appetitive noncontingent test. The dogs were divided into six groups: (1) a group immunized by controllable and predictable noise (CP), (2) a group immunized by controllable but unpredictable noise (CU), (3) a group immunized by uncontrollable but predictable noise (UP), (4) a group given un- 
controllable and unpredictable noise during immunization training (UU), (5) a group not submitted to any treatment during the immunization phase (NI), and (6) a group not submitted to any treatment (NN). During inescapable noise training, all groups, except Group NN, were given inescapable noise; Group NN did not receive any treatment during either the immunization phase or inescapable noise training.

Appetitive contingent training. On the evening prior to the experiment, the dogs were given $300 \mathrm{~g}$ of minced meat in their usual compartments so that they could get used to the type of food that they would be given throughout the experiment. On the following day, each animal was put in the contingent appetitive conditioning compartment and, for $2 \mathrm{~min}$, it was allowed to eat $50 \mathrm{~g}$ of food divided into five lots of $10 \mathrm{~g}$ of food. Immediately after the $2 \mathrm{~min}$ elapsed, a 30-min session began in which the animals were given $10 \mathrm{~g}$ of food for pushing the lever on a fixed-ratio schedule (FR-1). These sessions were repeated for 10 min every day, but with an FR-2 schedule, until the animal had eaten a total of $1 \mathrm{~kg}$ of food over all the sessions. The animals required an average of 4.5 sessions to meet this criterion. The dogs that did not reach 10 responses in the first three sessions, and those that exceeded the $1-\mathrm{kg}$ criterion, were eliminated from the study. When all of the dogs had reached the criterion, an additional session was set up. The dogs were then assigned to the different experimental groups according to the number of responses emitted during this additional session; in this way, all of the groups were similar with regard to the acquisition of an appetitive response before noise training began. The number of sessions that each dog had needed to reach the established criterion was also taken into account when assigning the dogs to the different groups. All experimental sessions were carried out after $1400 \mathrm{~h}$, which was the dogs' usual time for food.

Immunization training. During this phase, the animals assigned to Groups CP and CU received 60 trials of escapable noise. They could stop the noise by pushing the lever placed in the center of the cubicle (FR-1). The noise was presented on a random-time 60 sec schedule (RT 60); if the dog did not make the escape response (push the lever), the noise lasted for $30 \mathrm{sec}$. In addition, a 1-sec light stimulus appeared $2 \mathrm{sec}$ before the occurrence of the noise in the group trained with predictable noise (CP). Therefore, there was a 1 -sec gap between the end of the light stimulus and the beginning of the noise. Group $\mathrm{CU}$ was not given the light stimulus. All of the animals in both of these escape groups successfully managed to escape the last 15 noises and showed a decrease in their response latencies during the last 10 noises. During the $60 \mathrm{~min}$ that the immunization training session lasted, the animals in both of these escapable noise groups received an average of $324.5 \mathrm{sec}$ of noise ( $327.12 \mathrm{sec}$ for Group CP and $331.88 \mathrm{sec}$ for Group CU); the groups did not differ in their mean time $[t(10)=1.33, p=.212]$.

Groups UP and UU were introduced into the experiment to control for the effects of exposure to noise. Once in the corresponding compartments, the animals in these two groups received 60 noise trials of the same intensity and duration as that experienced by their respective partners in the groups given escapable noise.

The animals in the remaining two groups (NI and NN) were put in the compartment for a period equal to that of the other four groups, but they did not receive any kind of treatment.

Inescapable noise training. On the day after immunization training, five of the six groups were exposed to a $1-\mathrm{h}$ inescapable noise session. This session consisted of random presentations of 60 inescapable and unsignaled 30 -sec noises. The sixth group (NN) was put in the same compartment for the same time period but was not exposed to the noise.

Recovery. On the day after exposure to inescapable noise, the dogs remained undisturbed in their home cages. On each of the following 2 days, the dogs were put in a new compartment for $60 \mathrm{~min}$ each day. The purpose of this step was to minimize the possible transfer of conditioned fear to contextual cues in the animals previously exposed to inescapable noise.

Appetitive noncontingent test. On the 4th day after exposure to inescapable noise, the dogs were taken back to the operant conditioning compartments used during contingent appetitive training and were put through a 10 -min noncontingent appetitive conditioning session. In the course of this session, the dogs were given 20 reinforcements (each consisting of $10 \mathrm{~g}$ of minced food) on a randomtime 30-sec schedule (RT 30). Therefore, reinforcements were independent of the dogs' responses. The number of responses emitted by each dog during this session was taken as the dependent variable.

\section{RESULTS}

Table 1 shows the number of operant responses made by each dog during the appetitive noncontingent test and the means and standard deviations for each group. The analysis of the responses emitted by each group revealed significant differences among them $[F(5,30)=43.78$, $p<.001]$. Table 2 shows the results of pairwise tests of the differences between groups.

Table 1

Number of Responses Emitted by Each Group in the Noncontingent Phase of the Experiment

\begin{tabular}{ccccrrr}
\hline & \multicolumn{6}{c}{ Group } \\
\cline { 2 - 7 } & CP & CU & UP & UU & NI & NN \\
\hline & 74 & 48 & 52 & 21 & 11 & 77 \\
& 66 & 57 & 29 & 6 & 7 & 84 \\
& 62 & 41 & 49 & 13 & 6 & 58 \\
& 50 & 32 & 38 & 8 & 2 & 93 \\
& 78 & 47 & 23 & 27 & 9 & 68 \\
& 69 & 39 & 55 & 16 & 17 & 72 \\
$M$ & 66.50 & 44.00 & 41.00 & 15.17 & 8.67 & 75.33 \\
$S D$ & 9.87 & 8.63 & 13.10 & 7.94 & 5.09 & 12.29 \\
\hline
\end{tabular}

Note-CP $=$ immunization with controllable-predictable noise, $\mathrm{CU}=$ immunization with controllable-unpredictable noise, UP = immunization with uncontrollable-predictable noise, $\mathrm{UU}=$ group given uncontrollable-unpredictable noise during immunization training, $\mathrm{NI}=$ group not immunized but subjected to helplessness, NN = group neither immunized nor subjected to helplessness.

Table 2

Difference Between Each Pair of Groups

\begin{tabular}{cllccc}
\hline & \multicolumn{5}{c}{ Group } \\
\cline { 2 - 6 } Group & CP & CU & UP & UU & NI \\
\hline CU & .022 & & & & \\
UP & .006 & n.s. & & & \\
UU & .001 & .002 & .006 & & \\
NI & .001 & .001 & .001 & n.s. & \\
NN & n.s. & .001 & .001 & .001 & .001 \\
\hline
\end{tabular}

Note-The central values indicate the probability (Scheffé) associated with each comparison between two groups (n.s. = not significant, $p>.10) . \mathrm{CP}=$ immunization with controllable-predictable noise, $\mathrm{CU}$ = immunization with controllable-unpredictable noise, $\mathrm{UP}=\mathrm{immu}-$ nization with uncontrollable-predictable noise, $\mathrm{UU}=$ group given uncontrollable-unpredictable noise during immunization training, NI = group not immunized but subjected to helplessness, NN = group neither immunized nor subjected to helplessness. 
The nonimmunized animals (Groups UU and NI) emitted significantly fewer responses than did the animals in the control group (NN). This suggests, as predicted by helplessness theory, that inescapably shocked animals are more sensitive than nonshocked animals to instances of response-reinforcer independence.

Second, the three immunized groups (CP, CU, and UP) made significantly more responses than the nonimmunized animals (Groups UU and NI). However, only the animals in Group CP made as many responses as the animals in Group NN, and their average response rate was significantly higher than the rates in the partially immunized groups (CU and UP). Although the animals in both partially immunized groups emitted significantly more responses than the animals in the nonimmunized groups, they did not reach the level of the control group (see Table 2).

\section{DISCUSSION}

The results of this experiment show that it is possible to immunize animals against the effect of exposure to inescapable aversive stimulation even when that effect takes the form of reduced responding when the presentation of food is independent of responding. As we expected, the inescapably shocked animals were more sensitive to the response-reinforcer independence than were the nonshocked animals, and the immunized animals behaved like the nonshocked animals.

This leads us to conclude that the failure of previous experiments to achieve immunization in noncontingent contexts (Warren et al., 1985) occurred because those investigators neglected the unpredictability of the aversive stimuli used in their experiments. In our experiment, only the animals subject to controllable (escapable) and predictable aversive stimuli (total immunization) behaved like the control group during the noncontingent test.

However, in the test phase of the experiment, even though the dogs in Groups CU and UP did not reach response levels as high as those of the control group or the dogs in Group CP, the animals in the former groups did respond more often than the nonimmunized animals. This result leads us to believe that both components of the immunizing stimulus (controllability and predictability) are able, separately, to produce some degree of reduction in the effects produced by exposure to inescapable noise. Thus, our results failed to replicate those of Warren et al. (1985), who did not find even partial immunization in a noncontingent test.

According to Overmier (1985), the deficits produced by exposure to inescapable aversive stimulation are due to the fact that such stimulation is uncontrollable and unpredictable. If this is so, why is it that in noncontingent contexts it is necessary to train animals with controllable and predictable stimuli in order to fully immunize them, whereas in contingent contexts it is sufficient to train them with controllable stimuli (Warren et al., 1985)?
The answer to this question was alluded to in the introduction. According to Overmier's bifactorial theory. the two components responsible for the helplessness syndrome (uncontrollability and unpredictability) are independent of each other, the uncontrollability component being the fundamental cause of the motivational deficit and the unpredictability component being responsible for the associative deficit. Assuming this, it might be expected that an animal trained in total immunization should respond adequately in both a contingent and a noncontingent situation. Because of the training it has received, the animal still thinks that its responses and the reinforcements are related (immunization against the associative deficit), and its ability to initiate new responses remains intact (immunization against the motivational deficit). However, this should not happen with animals partially trained in immunization. If an animal is trained with controllable but unpredictable stimuli, the achieved immunization will affect its ability to initiate new responses (immunization against motivational deficit). However, its perception of the relationship between its responses and the consequences thereof will be similar to that of the animals in Group NI. If the animals in Group CU are put through a contingent test situation, the responses that they initiate will result in reinforcement and, thus, its response-reinforcement relationship will change. The animals will then behave as if the helplessness training had not had any effect. That is, they will be totally immunized. On the other hand, even if the animal is tested in a noncontingent situation, the presence of the associative deficit will cause it to respond less frequently than the animals in Group NN. However, because it does not have a motivational deficit, the animal will begin the test by responding at a higher rate than the animals of Group NI (which do have a motivational deficit), and it will therefore be partially immunized.

The fact that the animals in Group UP were partially immunized (i.e., made more responses in the test than did the controls) cannot be clearly explained. The use of a choice response instead of a persistence measure would probably help us better identify and interpret the immunization effect.

In conclusion, we emphasize the fact that the results of this experiment represent the first empirical demonstration of the possibility of obtaining immunization in noncontingent contexts. Our results can also be interpreted in the context of one of the latest reformulations of learned helplessness theory (Overmier, 1985). In order to confirm these findings, it will be necessary to replicate our experiment with other animals, varying the type of motivational context and the amount of training used.

\section{REFERENCES}

AвBotT, B. B. (1985). Rats prefer signaled over unsignaled shock-free periods. Journal of Experimental Psychology: Animal Behavior Processes, 11, 215-223.

Abbott, B. B., Schoen, L. S., B Badia, P. (1984). Predictable and 
unpredictable shock: Behavioral measures of aversion and physiological measures of stress. Psychological Bulletin, 96, 45-71.

Alloy, L. B., \& TABachnik, N. (1984). Assessment of covariation by humans and animals: The joint influence of prior expectations and current situational information. Psychological Review, 91, 112-149.

Altenor, A., Kay, E., \& Richter, M. (1977). The generality of learned helplessness in the rat. Learning \& Motivation, 8, 54-61.

anisman, H., Irwin, J., Beauchamp, C., \& Zacharko, R. (1983). Cross-stressor immunization against the behavioral deficit introduced by uncontroliable shock. Behavioral Neuroscience, 97, 452-461.

Badia, P., Harsh, J., \& ABbott, B. (1979). Choosing between predictable and unpredictable shock conditions: Data and theory. Psychological Bulletin, 86, 1107-1131.

Dess, N. K., Linwick, D., Patterson, J., Overmier, J. B., \& LeVINE, J. (1983). Immediate and proactive effects of controllability and predictability on plasma cortisol responses to shocks in dogs. $B e-$ havioral Neuroscience, 97, 1005-1016.

Ferrándiz, P., Olea, J., \& PArdo, A. (1985). Efecto modulador del rasgo introversión-extroversión sobre el entrenamiento en indefensión aprendida. Boletín de Psicologia, 9, 99-117.

Jackson, P. L., Alexander, J. H., \& Maier, S. F. (1980). Learned helplessness, inactivity and associative deficits: Effects of inescapable shock on response choice escape learning. Journal of Experimental Psychology: Animal Behavior Processes, 6, 1-20.

Maier, S. F., \& Seligman, M. E. P. (1976). Learned helplessness. Theory and evidence. Journal of Experimental Psychology: General, 105, 3-46.

Mullins, G. P., \& WiNEFIELD, A. H. (1977). Immunization and helplessness phenomena in the rat in a nonaversive situation. Animal Learning \& Behavior, 5, 281-284.

OVERMIER, J. B. (1985). Toward a reanalysis of the causal structure of the learned helplessness syndrome. In F. R. Brush \& J. B. Overmier (Eds.), Affect, conditioning and cognition: Essays on the determinants of behavior (pp. 211-227). Hillsdale, NJ: Erlbaum.

Overmier, J. B., \& Seligman, M. E. P. (1967). Effects of inescapable shock upon subsequent escape and avoidance behavior. Journal of Comparative \& Physiological Psychology, 63, 23-33.

OVERMIER, J. B., WIELKIEWICZ, R. M. (1983). On unpredictability as a causal factor in learned helplessness. Learning \& Motivation, 14, 324-337.

Rosellini, R. A., \& DeCola, J. P. (1981). Inescapable shock interferes with the acquisition of a low-activity response in an appetitive context. Animal Learning \& Behavior, 9, 487-490.

Rosellini, R. A., DeCola, J. P., Plonsky, M., Warken, D. A., \& Stilman, A. J. (1984). Uncontrollable shock proactively increases sensitivity to response-reinforcer independence in rats. Journal of Experimental Psychology: Animal Behavior Processes, 10, 346-359.

Rosellini, R. A., DeCola, J. P., \& Shapiro, N. R. (1982). The crossmotivational effects of inescapable shocks are associative in nature. Journal of Experimental Psychology: Animal Behavior Processes, 8, 376-388.

Seligman, M. E. P. (1972). Learned helplessness. Annual Review of Medicine, 23, 407-411

Seligman, M. E. P. (1975). Helplessness: On depression, development, and death. San Francisco: W. H. Freeman.

Seligman, M. E. P., \& Groves, D. P. (1970). Nontransient learned helplessness. Psychonomic Science, 19, 191-192.

Seligman, M. E. P., \& Maier, S. F. (1967). Failure to escape traumatic shock. Journal of Experimental Psychology, 74, 1-9.

Seligman, M. E. D., Maier, S. F., \& Solomon, R. L. (1971). Unpredictable and uncontrollable aversive events. In F. R. Brush (Ed.), Aversive conditioning and learning (pp. 347-400). New York: Academic Press.

Seligman, M. E. P., Rosellini, R. A., \& Kozak, M. (1975). Learned helplessness in the rat: Reversibility, time course, and immunization. Journal of Comparative \& Physiological Psychology, 88, 542-547.

Warren, D. A., Rosellini, R. A., Plonsky, M., \& DeCola, J. P. (1985). Learned helplessness and immunization: Sensitivity to response-reinforcer independence in immunized rats. Journal of $E x$ perimental Psychology: Animal Behavior Processes, 11, 576-590.

Williams, J. L., \& MaIER, S. F. (1977). Transsituational immunization and therapy of learned helplessness in the rat. Journal of Experimental Psychology: Animal Behavior Processes, 3, 240-253.

(Manuscript received July 7, 1988; revision accepted for publication October 21, 1989.) 